\title{
Collaborative and self-generated analogies in science education
}

\author{
Jesper Haglund
}

\section{Linköping University Post Print}

\section{Tweet}

N.B.: When citing this work, cite the original article.

This is an Author's Accepted Manuscript of an article published in Studies in Science Education, 2013.

Copyright: Taylor \& Francis (Routledge) (http://www.routledge.com/)

Available online at: http://www.tandfonline.com/10.1080/03057267.2013.801119

Postprint available at: Linköping University Electronic Press http://urn.kb.se/resolve?urn=urn:nbn:se:liu:diva-92715 
Collaborative and self-generated analogies in science education

\section{Jesper Haglund}

Department of Social and Welfare Studies (ISV), Linköping University, Norrköping, Sweden

Address:

Linköping University

Department of Social and Welfare Studies (ISV)

SE-601 74 Norrköping

Telephone: +46-11-363364

Fax: +46-11-363004

Email address: jesper.haglund@liu.se

Requested information:

Word count: 18664

The manuscript is not intended for a special issue. 


\title{
Collaborative and self-generated analogies in science education
}

\author{
It has long been recognised that analogies may be a useful tool in science \\ education. At the same time, it has been found that there are challenges to using \\ analogies in teaching. For example, students might not identify a suitable \\ analogy, might not recognise how the taught target domain is similar to the \\ source domain to which it is compared, or may fail to realise where the analogy \\ breaks down. The present study offers a review of two trends which reflect the \\ ambition to come to terms with such challenges: self-generated analogies, \\ making use of students own analogies in teaching, and; analogy generation in \\ collaborative settings, such as in small group work. Empirical studies show \\ predominately positive results with regards to students' enjoyment and learning \\ gains, and point to opportunities for formative assessment. The specificities of \\ language in conjunction with analogy and the role of analogies in authentic \\ science classroom discourse are suggested as areas of study that deserve more \\ attention going forward.
}

Keywords: analogical reasoning; spontaneous analogy; self-generated analogy; collaboration; production paradigm

\section{Introduction}

The use of analogies has long been recognised as a possible tool for improving students' conceptual understanding in science education, and many different teaching approaches have been developed in order to make full advantage of them (Aubusson, Harrison, \& Ritchie, 2006; Duit, 1991). The core of analogical reasoning is to think about a new, typically more abstract area of knowledge, a target domain, by comparing it to a known and more concrete area of knowledge, a source (or base) domain. In this way, analogies are particularly attractive to educational perspectives that emphasise what students already know as a starting point for teaching and learning, including constructivism with its focus on students' building their own knowledge, and studies on the issue of transfer, applying in a new context what has been learnt in another. However, it has also 
been found that teaching and learning with analogies is not unproblematic, as it comes with many challenges for teachers and students. For example, students may not realise that they can make use of analogical reasoning when trying to solve a particular problem (Gick \& Holyoak, 1980), students may make other connections and inferences than those that the teacher has intended (Zook, 1991), students do not scrutinise where a particular analogy breaks down (Glynn, 1989), or they get a one-sided, oversimplified view of the subject area to be learnt (Spiro, Feltovitch, Coulson, \& Anderson, 1989). The present review focuses on two different, but interrelated trends in science education research and practice with regards to analogical reasoning: First, some of the challenges mentioned above may be taken on by paying more attention to students' spontaneous analogies or asking them to come up with their own self-generated analogies. Second, students' learning through analogy generation might benefit from collaborative work, for example in small-group problem-solving exercises or role play. The review builds in parts on my doctoral dissertation and articles that are included in it in the form of a compilation (Haglund, 2012). The main contribution of this review is that it brings together and puts in context studies that recognise the potential use of students' own analogies in science education, as opposed to the previously dominating teacher-generated analogies that are provided by the teacher or taken from textbooks. In particular, in light of the increasing influence of socio-cultural perspectives on learning, the review puts forward studies that have focused on students' generation of analogies in social settings and points forward to research on the role of language in collaborative analogy generation.

Before these trends are explored, I first provide a background of different views of what analogies and analogical reasoning are, how analogical reasoning has been 
approached in psychology and in relation to scientific modelling, and, particularly, in foundational science education research.

\section{Analogical reasoning}

\section{What are analogies?}

Dedre Gentner (1983) has developed the 'structure-mapping theory' as an account of the structure of analogy and the process of analogical reasoning. Overall, analogy involves mapping an encountered area of knowledge, a target domain, to another presumably better known or more concrete area of knowledge, a base or source domain. Domains are psychologically interpreted systems of objects, attributes of the objects, and relations between the objects. Analogies differ from other types of domain comparisons in that they emphasise similarities in the relational structure across the domains, but not on similarities in the attributes. Gentner exemplifies with the Rutherford-Bohr analogy between the structure of the atom and a solar system, where the central atomic nucleus corresponds to the sun and stands in a relation to smaller orbiting electrons, the counterpart of the planets in the solar system. The analogy goes beyond surface similarities, i.e. any shared attributes of the constituting objects: a focus on the sun being warm and yellow would in fact give a misleading idea of the atom. Cases where comparisons are based on matches of both attributes and structural relations, for instance when comparing our solar system to that of another star, are classified as literal similarities. Another type of comparison, abstraction, focuses on the shared principle between the two involved domains, here that the atom and a solar system may be interpreted as two examples of central force systems. In the structuremapping theory, Gentner further proposes a systematicity principle, in that we favour mappings that are coherent and of high structural order, where a first-order relation is a 
relation between objects, a second-order relation a relation between first-order relations, etc.

The development of the structure-mapping theory by Gentner and colleagues (e.g. Falkenhainer, Forbus, \& Gentner, 1989; Gentner, 1983) has been based on psychological experiments and computer models of the cognitive processing. The theory has been influential in cognitive psychology and - the primary focus of this article - in science education research. However, it has not remained unchallenged, but has rather acted as a kind of touchstone, against which new initiatives and findings have been tested and discussed. For instance, in their theory of analogy as constraint satisfaction, Holyoak and Thagard (1989) point out that Gentner's (1983) focus on structural similarity is only one among multiple constraints that influence our analogical reasoning. There are also pragmatic constraints, such as a person's awareness that searching for analogies might be a useful approach to solving a particular problem, and semantic constraints, such as the particularities of the concepts in the involved domains and commonalities of objects and their attributes across the domains. In addition, Chalmers, French and Hofstadter (1992) question the feasibility of exclusively cognitive approaches to analogies and analogical reasoning. Instead of seeing cognition as working in isolation, provided with sensory data from the perceptual system, they propose a more integrated view, where we recruit concepts and memories from our cognition in making sense of situations we encounter through high-level perception. For instance, very different concepts are brought to mind if we are presented with the analogies where DNA is compared to a zipper or a computer's source code, respectively. The other way around, our perception depends on analogy generation from cognition, making us able to see a situation in terms of another. 
As an interlude, it is necessary to comment on the relation between analogy and metaphor. As a figure of speech described in ancient Greece, a metaphor has the structure ' $\mathrm{X}$ is $\mathrm{Y}$ ', but goes beyond the literal truth of the sentence. For example, with the statement 'my boss is a pig', an employee does not primarily intend to convey that his immediate superior is a porcine mammal - which a literal interpretation would yield - but rather allude to his questionable behaviour and moral character or possibly his personal hygiene; hence a metaphor. The meaning of metaphor is often widened to represent other forms of figurative language, not strictly following the form ' $\mathrm{X}$ is $\mathrm{Y}$ ', such as 'one giant leap for mankind'. In this text, I largely adhere to Gentner's view, encapsulated in the title Metaphor is like analogy (Gentner, Bowdle, Wolff, \& Boronat, 2001), in the sense that metaphor and analogy are both based on domain comparisons and are often used interchangeably. ${ }^{1}$ More specifically, however, I regard metaphor as primarily a linguistic phenomenon, typically involving some aspect of surprise and tension which is left to the reader to interpret, while analogy is attributable to the level of cognition and typically involves pointing out correspondences across domains

\footnotetext{
${ }^{1}$ It should be noted, however, that this view is challenged by Glucksberg and colleagues (e.g. Glucksberg \& Keysar, 1990), who argue that metaphor is based on category inclusion, rather than domain comparison. For instance, when I say that 'my job is a jail', I do not compare the domains, but categorise 'my job' as belonging to the category 'jail', representing confining, unpleasant institutions. In response, Bowdle and Gentner (2005) have suggested a career of metaphor, according to which novel metaphors are interpreted as comparisons, while conventionalised metaphors rely on category inclusion. Within the field of science education, Atkins (2004) argues, bringing Glucksberg and Keysar's (1990) ideas one step further, that not only metaphor, but also analogy, as expressed in authentic classroom science discourse, are better characterised as categorisation phenomena, rather than in terms of comparison.
} 
explicitly. What starts as a metaphoric expression may well be elaborated into an analogical comparison between the two involved domains.

Many early foundational studies on analogical reasoning and the related fields of metaphors and mental modelling have been published in three influential anthologies: Metaphor and thought, edited by Ortony (1979/1993), Mental models, edited by Gentner and Stevens (1983), and Similarity and analogical reasoning, edited by Vosniadou and Ortony (1989). More recent findings on analogical reasoning have been collated in the anthology The analogical mind, edited by Gentner, Holyoak and Kokinov (2001), and Holyoak (2012) provides an up-to-date overview of analogies, including insight from the field of neurocognition. We will have the opportunity to touch upon some of these studies in the following.

\section{Analogical reasoning in a developmental perspective}

The question of at what age children come to develop the ability to reason by means of analogy has been of interest in cognitive and developmental psychology. Laboratory tests of analogical reasoning are often based on solving tasks of the structure A:B::C:D, i.e. what relates to $\mathrm{C}$ in the same way as $\mathrm{A}$ relates to $\mathrm{B}$. For instance, when presented with 'cat is to kitten as dog is to ...?', a respondent is supposed to answer 'puppy'.

From a study where participants of different ages were asked to pick out the most appropriate picture representing the ' $\mathrm{D}$ ' answer from a selection of cards, Piaget, Montangero and Billeter (1977/2001) conclude that analogical reasoning is not fully developed until Piaget's formal-operational stage, typically entered at the age of 11-12 years. Subsequent studies, however, have found that substantially younger children, as young as 3 and 4 years old, are capable of performing analogical reasoning, provided that the source domain is properly understood and that they have grasped the task of 
coming up with analogies (Brown, 1989; Goswami, 1992), in line with Holyoak and Thagard's (1989) recognition of semantic and pragmatic constraints. Goswami (1992) even conjectured that analogical reasoning is an innate ability of infants, a view which later has been supported by Gentner (2003) with regards to structure mapping in general, but also criticised by Richland, Morrison and Holyoak (2006), who argue that analogical reasoning is dependent on the gradual development of the working memory capacity to manipulate complex information. Holyoak (2012) shows that success at tasks involving analogies has a high correlation with results from intelligence tests, which are known to be highly age dependent. Overall, Gentner (1989) suggests that there may be a relational shift in the reasoning of children, from a reliance on attribute similarities of 5-year-olds to a recognition of relational structure among 9-year-olds.

\section{Analogical reasoning in historical and current science}

Apart from cognitive psychology, another academic field that has taken an interest in analogical reasoning is the history and philosophy of science. Black (1962) argues that analogical extension from one domain of study to another is a powerful approach in scientific modelling, not only in communicating the results of research, but also as part of the creative act of conducting research. Analogies share with scientific models the characteristic that they are representations in which certain aspects of a phenomenon are emphasised, while others are played down or completely ignored. In particular, Hesse (1966) points out that in comparisons between domains, there may be aspects of positive analogy, features that are known to be shared across the domains, and negative analogy, where the domains are known to differ, but most interestingly also neutral analogy, yet undecided correspondences, which may be used for generation of hypotheses and guiding further investigation. 
From a historical point of view, Gentner and Jeziorski (1993) suggest that there was a shift in Western science from an earlier focus on metaphoric associations across domains to a more modern focus on relational structures. For instance, in mediaeval times, Mars was seen as an ancient war God, connected to the metal iron, masculinity and the name of a planet, the red colour of which is due to iron oxides; a loose chain of associations. In contrast, even though Sadi Carnot based his investigation of heat on the later abandoned caloric theory, Gentner and Jeziorski see his waterfall analogy as an early representative of the modern approach. Carnot compared the heat flow from an object of higher temperature to an object of lower temperature to a waterfall from a higher to a lower level of water, explicitly pointing out correspondences between the two domains, in line with the structure mapping theory (Gentner, 1983).

With her cognitive-historical approach, Nersessian (2008) has investigated how Maxwell used insight into mechanics and machine design in drawing analogies in his development of a theory of electromagnetism. One finding is that analogical reasoning rarely comes alone, in contrast to psychology laboratory experiments of the use of analogy in problem solving. Rather, analogies are used in conjunction with other nonformal ways of reasoning, such as imagery and thought experiment. Further, the level of complexity is much higher in these more authentic examples than in the typical psychology laboratory set-ups. First, there is no clear-cut solution to the target problem to be discovered in the source domain. Instead, she describes an iterative process of bootstrapping where: 'each domain supplies constraints that can be looked at as one of the straps, the intermediary hybrid models are strap crossings, and each crossing supports or contributes to further model building and enhanced target understanding' (Nersessian, 2008, p. 133, italics in the original). In this way, Maxwell used analogical reasoning to gradually build his understanding of the phenomenon at hand, an extended 
process in which identifying a suitable source domain is only the first step. Nersessian points to another contribution to complexity in that, as opposed to Gentner's (1983) account of structure mapping, there is no limitation to one source domain only when approaching a target phenomenon in such authentic analogical reasoning. Maxwell, for instance, started by investigating the connections between magnetic phenomena and mechanics by modelling the rotation of one vortex in isolation. However, investigation of electromagnetic phenomena required modelling interaction between several vortices, which would cause jamming due to friction in the mechanics source domain. Maxwell therefore recruited insight into engineering mechanics in seeing the turning vortices in terms of cog-wheels, some of which are idle. In this way, Nersessian offers insight into the intricacies of Maxwell's theory development and the breadth of knowledge and imagination that he needed to deploy in carrying out the analogical reasoning. As a reflection, this calls for humility in our expectations of students' ability to make use of analogies in a productive way in science education.

Cognitive science has also studied how current scientists make use of analogical reasoning. Dunbar and Blanchette (2001) suggest that a combination of controlled psychology laboratory in vitro studies of scientists being exposed to problem-solving tasks and ethnographic in vivo studies of scientists' work in authentic professional science contexts, might be fruitful in charting their analogical reasoning and cognitive phenomena at large.

Clement (1988) reports on a study in the in vitro tradition, where he asked expert scientists to consider a weight hanging on a metal spring, and ascertain how the extension of the spring would be affected by an increase in the diameter of the spring, all other things, e.g. the material and the number of coils, being equal. Similar to Nersessian's (2008) later findings with regards to historical scientists, Clement (1988) 
found that the contemporary scientists make extensive use of many non-formal ways of reasoning - such as mental simulation, visual imagery and analogical reasoning. In particular, they often made use of a series of slight alterations to the problem, such as imagining the bending of a straight rod and considering square and hexagonal coils as intermediary bridging analogies in comparison with the spring. The ubiquity and usefulness of such gradual transformations led Clement to argue for a more inclusive view on analogy, encompassing also comparisons which might be considered as literal similarities in Gentner's (1983) classification.

As part of the in vivo tradition, or studying cognition in the wild (Hutchins, 1995), Schön (1993) has followed a group of product-design researchers as they developed paintbrushes with synthetic bristles. Many problems that the group initially was confronted with could be handled once they realised that the paintbrush could be regarded as a kind of pump, where paint was allowed to flow in the gaps between the bristles. He gives this paintbrush-as-pump as an example of a generative metaphor, 'a special version of SEEING-AS by which we gain new perspectives on the world' (Schön, 1993, p. 138). In this case, 'everything one knows about pumping has the potential of being brought into play in the redescription of painting' (Schön, 1993, p. 141), which was found to be beneficial in the technological development. Another example of how scientists use cognitive resources in representing and solving authentic research problems in social contexts is given by Dunbar (1995), who followed activities in four molecular biology laboratories for one year. Analogies were found to be an important feature of the scientists' reasoning. First, local analogies within the same domain were often used, particularly in the setting when they had problems with an experiment and tried to solve them by comparison to other, similar, but successful experiments. In addition, regional analogies between two domains belonging to a common class, for 
example phage viruses and retro viruses, were used in elaboration of theories, generation of hypotheses and experiment design. Finally, long-distance analogies between domains far apart were used to highlight salient features of the research when introducing new staff members to the work. However, in line with Clement (1988) - but in contrast to Schön (1993) - such long-distance analogies were not involved in the phase of making new discoveries.

Once an analogy has been identified between fields that hitherto have been regarded as unconnected, this idea may be used in further exploration of the investigated target phenomenon. For instance, Boyd (1993) points out that the metaphor of the mind as a computer lay the foundation for the field of cognitive science, but, as recognised by Hutchins (1995), the metaphor has also constrained the way cognitive science has developed. In addition, powerful metaphors and analogies may soon find their way to the public through popular accounts and the educational system. As an example, Knudsen (2003) tracks how the idea of a genetic code and its translation involved in genetic expression was used first within the science community, but later also adopted in everyday language.

\section{Analogies in science education}

Using analogies as part of teaching - comparing a topic to be learnt, a typically abstract target domain, to a more familiar and/or concrete source domain - has been widely adopted in science education. Duit (1991) provides an overview of different theoretical and practical approaches to the issue, which had been developed up until the early 1990s. His overview is nicely complemented by more recent findings in the anthology Metaphor and analogy in science education, edited by Aubusson, Harrison and Richie (2006), and parts of the following builds on these two accounts. Also Dagher (1998) 
gives a concise overview of different approaches to the field of study.

Overall, Duit (1991) argues that the use of analogy fits particularly well with a constructivist approach to teaching, which emphasises learning as an active constructive process on the part of the learner and that learning builds on the learner's prior knowledge. As an example, Gentner and Gentner (1983) studied how exposure to two different analogies, comparison to flowing water vs. a teeming crowd, influenced students' conceptualisation of electric circuits. They found that the students' approaches to and success at solving different tasks involving series and parallel electric circuits varied depending on what analogy they had been engaged with. Duit (1991) concludes that analogies are valuable tools for conceptual change in science education, but that the use of analogies in teaching is not unproblematic, since - as we shall see - it confronts teachers and learners with many challenges.

In psychology laboratory experiments, Gick and Holyoak (1980) first presented subjects with the problem of invading a fortress by dividing the forces and attacking it from all directions, and then asked them to solve the problem of radiating a tumour without damaging the surrounding tissue. According to the researchers, these two problems share an underlying structure and it would be suitable to solve the radiation problem by analogy to the fortress problem. However, intriguingly, few of the subjects spontaneously came to see the similarity across the problems. With explicit hints to make use of the solution to the previous problem, more of the subjects did so, which, as we have seen, Holyoak and Thagard (1989) have later explained in terms of pragmatic constraints on analogical reasoning. Framed as a potential challenge in science teaching, teachers cannot assume that their students will readily realise that two domains may be structurally or functionally similar; it may need to be explicitly pointed out. 
Even if students grasp the basic idea of an analogy - that a taught topic is supposed to be similar to another domain - another challenge is to realise in what respect the two domains are similar and where they might differ. First, for young children, and generally when we are not knowledgeable about a domain, it is tempting to focus on surface similarities, rather than the shared relational structure of the constituent entities in two compared domains. For instance, using Gentner's (1983) example of the atom/solar-system analogy, we might well pick up the attributes of the sun, and erroneously infer that also the atomic nucleus is huge, warm and yellow. Next, having adopted a structural focus, we still have to be aware of the fact that all features of a source domain cannot be transferred to a target domain, as, in Hesse's (1966) terminology, there are also neutral or negative analogies. With regards to the analogy between the atom and solar systems, Taber (2001) points out a number of features that may lead learners astray: the planets attract each other, but the corresponding electrons repel each other; planets are composite bodies, differing in size and constitution, while electrons are identical and considered fundamental; planets have moons, electrons do not, etc. As part of their critique of structural approaches to metaphors and analogies (e.g. Gentner, 1983), Carroll and Mack (1985) contribute to this list of characteristics that should not be carried over from the domain of solar systems to that of atoms, including the salient relationship of the sun heating the planets. In addition, as pointed out by Holyoak and Thagard (1989), our previous experience and knowledge of the phenomena at hand provide semantic constraints to the ability to draw analogies and the depth to which they are developed. For instance, going back to the tumour radiation problem (Gick \& Holyoak, 1980), with a more advanced knowledge of cancer therapy, the idea of approaching a tumour from many directions could have been generalised to a compound treatment, including physical surgery, radiation and chemotherapy, even 
though this does not seem to have been the researchers' intention. Accordingly, Glynn (1989, p. 198) asserts:

Teachers and authors should explain to students that analogies are double-edged swords. An analog can be used to correctly explain and even predict some aspects of the target concept. At some point, however, every analogy breaks down. At that point, miscomprehension and misdirection can begin.

Students have to be aware that an analogy picks out only certain aspects of a target phenomenon or concept, but they will also need guidance in understanding what aspects to focus on in each particular case of analogy use. Heywood and Parker (1997) offer the more positive perspective that once we realise that analogies break down at some point, this awareness may contribute productively to conceptual understanding, but also give insight into the nature of science:

...it is in the promotion of the critical scrutiny in challenging the analogy, attempting to apply it and recognising when and why it breaks down that the opportunity for learning really takes place. The focus is in this sense diverted from attempts to find the perfect analogy towards considerations of accepting that there are limits to understanding and that we need to encourage such intellectual engagement in order to promote effective teaching and learning in science. That is, to encourage learners to recognise that this is part of the scientific enterprise and to focus on the extent to which their understanding has developed (Heywood \& Parker, 1997, p. 883).

In this respect, paradoxically, the seemingly perfect analogy, approaching an isomorphic fit of identical structure between the source and target domains may even be counterproductive, since it does not invite such scepticism and scrutiny. In contrast, contrived or light hearted comparisons may result in a more playful attitude and more imaginative 'what if'-thinking. Coming back to the atom/solar-system analogy, Carroll and Mack (1985) suggest that according to classical physics, electrons rotating around a 
nucleus would emit electromagnetic radiation and thereby rapidly lose their kinetic energy and plunge into the nucleus. This does not happen for atoms. In fact, this negative analogy provided an anomaly for the preceding theory, which contributed productively to the development of quantum physics. In my mind, this attraction of imperfection is captured succinctly by Leonard Cohen (1992) in his song Anthem: 'There is a crack in everything. That's how the light gets in'.

Against the background of an awareness of such opportunities and pitfalls, many different approaches and frameworks involving teaching with analogies have been developed as part of science education research. Using examples from biomedicine, including the function of muscle fibres, Spiro, et al. (1989) suggest that one way to come to terms with the idiosyncrasies of each individual analogy and the risk of students forming misconceptions when interacting with them, is to provide the students with several multiple analogies to a phenomenon. If selected carefully, these different analogies may emphasise different aspects of the phenomenon at hand in a complementary way, counteracting the negative features of each other, and as a whole bring across a more multifaceted, integrated view of the phenomenon. In addition, at a meta-level, presenting multiple analogies may contribute to an understanding that representations of phenomena are created deliberately to emphasise certain aspects and play down others; an important characteristic of the nature of science.

Clement (1993) proposes that a series of bridging analogies may be used in science teaching, providing the example of introducing normal forces, relating to his findings of scientists' use of a series of gradually modified analogies in problem-solving (Clement, 1988). According to Newtonian physics and as conceptualised by experts in this field, the forces that are exerted upon a book at rest are modelled in the same way if the book is placed on top of a table or if it visibly has compressed a metal spring 
downwards. Gravity pulls the book downwards, while the normal force from the table and spring, respectively, prevents it from moving downwards. However, it is challenging for students to conceptualise these two situations as instances of the same principle. Students have been found to associate forces to motion and displacement, and while these features are visible with respect to the yielding spring, this is not the case when book is placed on the table. To the novice, the domains are too far apart, and he or she cannot readily see what the situations have in common. Clement proposes that in order to facilitate the novices' interpretation, a series of bridging analogies might act as 'stepping stones', 'closing the gap' between these situations, so that they will be able to see the connection between the intermediary cases. With regards to the normal force being exerted on a book, Clement suggests introducing a yielding foam mattress and thin boards, preparing the students for a discussion of how also the microscopic structure of the table is yielding - although invisibly - to the weight of the book, providing a counterforce upwards. The instructional tactic of bridging analogies recognises Holyoak and Thagard's (1989) idea of semantic constraints in analogical reasoning. If corresponding entities in two different domains are seen as having the same role and meaning, here compressible, yielding objects, it is easier for us to see the underlying shared structure, which may be abstracted into a principle applicable to both situations, in this case exertion of normal force on a book. The approach also adheres to Dunbar's (1995) finding related to above of how scientists tend to use comparisons within domains or between closely related domains when they conduct research.

Zeitoun (1984) has developed the General Model of Analogy Teaching (GMAT) as a nine-stage model of how to conduct teaching involving analogies in a cycle of continuous revision and improvement. Activities in the model include: introducing the students to what analogies are; introducing them to the taught topic; providing the 
source domain; presenting analogous features across the domains; presenting irrelevant or non-matching features in order to avoid the formation of misconceptions; and, evaluating the learning outcome. As part of his model, Zeitoun offers three alternative teaching strategies of how to make use of analogies in teaching. First, with the guided teaching strategy, students are encouraged to investigate correspondences across domains for a given analogy and detect any irrelevant features, under the guidance of the teacher. Second, with the expository-teaching strategy, students are merely given the analogy, for example in text format, without instruction to unpack its finer details. Third, and most interestingly from the perspective of the present review, Zeitoun introduces the student self-developed analogy strategy. Here, students are encouraged to come up with their own analogies for a taught topic. He regards this strategy as a way for students to use analogies in their thinking, but acknowledges that it may be challenging to apply it in the learning of difficult concepts, about which the students have limited prior knowledge.

Similar to Zeitoun (1984), Glynn and colleagues (e.g. Glynn, 1989) have developed the Teaching with Analogies (TWA) model, with a particular focus on students' interpretation of textbooks. Glynn (1989) proposes the following steps for interpretation of analogies:

(1) Introduce the target domain

(2) Introduce the source domain

(3) Identify similar features across the domains

(4) Map the similar features explicitly

(5) Draw conclusions

(6) Identify where the analogy breaks down 
Treagust, Harrison and Venville (1998) made use of a modified TWA model (where steps 5 and 6 had been swapped) in an investigation of how experienced teachers apply their favourite analogies in their teaching. They argue that TWA would have to be complemented with the teacher's planning of the lesson and his or her post-class reflection and propose the Focus, Action, Reflection (FAR) guide for teaching with analogies. The preparatory Focus step involves thinking through whether the target and source domains might be familiar to and/or difficult for the students, Action involves the interaction with the students, with a focus on pointing out features that are shared or not shared across the domains. Reflection deals with drawing conclusions from the exercise and trying to improve it in future teaching. Within the FAR framework, Harrison and Coll (2008) have collated a set of analogies that they have found popular and reliable among teachers in biology, chemistry, physics and about earth and space at the middle and secondary school level.

\section{Collaborative and self-generated analogies in science education}

After this general introduction of different views on what analogies are and how they may be put to work in science and science education, we now turn to the review of the identified two trends in analogy use in science education: encouraging students to come up with their own analogies for taught topics; and encouraging students to generate and explore analogies in a collaborative fashion.

\section{The reception versus production paradigms}

Gentner (2003) argues that learning by analogy, in close connection with the use of symbol systems such as language, holds the answer to the foundational question of 'why we're so smart', in comparison to other related species. Similarly, Hofstadter (2001) puts forward analogy as 'the core of cognition'. Therefore, it is not surprising 
that we make use of analogical reasoning extensively and spontaneously as we try to make sense of the world around us. As we have seen, there are different views on how children acquire a capability to reason by analogy, but more recent accounts seem to converge at the conclusion that at least by the first school years, children have generally come to master this cognitive skill.

Against this background, Blanchette and Dunbar (2000) point to a paradox: if we are so good at analogical reasoning in general, how come we are confronted with so many challenges in making full use of this ability in the psychology laboratory or in educational settings? They argue that one way out of this conundrum is to distinguish between a reception paradigm and a production paradigm. In the reception paradigm, learners are supposed to receive an already existing analogy and interpret and use it in a particular, intended way. As we have seen, this is associated with many challenges, including: that the learners are supposed to have in-depth knowledge of the source domain, and that they have to identify the intended similarity between the domains. In the production paradigm, on the other hand, learners create analogies in order to organise what is known about a studied phenomenon and explore its properties. As we have seen, analogical reasoning is a thought process that is often used by researchers (Clement, 1988; Dunbar, 1995). If we apply the production paradigm to teaching with analogies, learners would generate their own analogies for a topic to be learnt. By default, if a learner comes up with a potentially suitable source domain, he or she has some idea of it and how it might be linked to the target domain, at least implicitly; otherwise it would not be considered as useful. In other words, by adopting the production paradigm, we may avoid some of the challenges identified in teaching with analogies. 
The majority of suggested approaches to the use of analogies in science education and empirical studies we have accounted for so far involve guides for teachers of how to generate analogies and convey them to their students in effective ways, i.e. they have been developed within the dominating reception paradigm. In contrast, the two trends we will trace in the following adhere to the production paradigm, in the sense that the students themselves generate their own analogies.

Even though this review has a particular focus on analogies, there are other lines of thought in science education research that are close to Blanchette and Dunbar's (2000) ideas of the production paradigm. Overall, the production paradigm aligns well with criticism of transmissive teaching and the advancement of student-centred teaching approaches, such as inquiry-based or discovery learning. It also picks out the creative element in constructivism; that learners have to produce or build their own knowledge, which is accentuated even further in Papert's notion of constructionism (Harel \& Papert, 1991), where learners' construction of knowledge typically comes in tandem with the construction of something external to themselves, such as a physical model or a poem. In particular, the production paradigm with regards to analogies relates to the recognition of students' ability to create their own representations for concepts and phenomena. Two examples are diSessa's (2004) emphasis on students' need to develop metarepresentational competences, including the abilities to invent or design new representations of phenomena and to evaluate the suitability of representations, and Ainsworth, Prain and Tytler's (2011).recognition of the potential in making your own drawings as a tool for learning.

As we will see, even though the production paradigm holds the hope of avoiding previously reported obstacles to analogical reasoning, it comes with its own challenges. As a contrast to arguments predominantly in favour of the production paradigm, Zook 
(1991) warns that education research has not sufficiently acknowledged the risk of students developing misconceptions as a consequence of teaching with analogies. $\mathrm{He}$ predicts that the process of mapping the source and target domains is particularly problematic in the case of teacher-generated analogies, but for analogies generated by the learners themselves, the most difficult process is the selection of appropriate source domains. Asking students to come up with analogies for a topic in relation to which they are complete novices is futile. They are likely to pick the first superficial feature that comes to mind and have little chance of identifying and carrying over the core ideas across domains. Such tasks can be introduced only when the students have embraced some of the crucial aspects of the topic to be learnt. Similarly, Clark (2006) cautions that in such constructivist approaches, students may spend too much time developing idiosyncratic explanations, rather than building a conception in line with the accepted science position. Clearly, using a production paradigm will not solve all challenges in science teaching, but provides yet another tool in the toolbox to consider in the educational practice and research.

\section{Spontaneous analogies and metaphors}

One possible use of students' ability to make comparisons is for teachers to attend to the students' spontaneous analogies and metaphors, associations and connections between domains that the students come up with in education without prior encouragement to do so. In line with the overall potential of the production paradigm, it is likely that a student who comes to see a taught topic as related to another topic in some way and chooses to bring it up in class, brings something valuable to the teaching. First, it offers the teacher and the other students a possible, new way to see the phenomenon at hand. Second, in contrast to analogies provided by the teacher, this student does not run the 
risk of not seeing that or how the two domains are connected to each other, thereby reducing the risk of misunderstandings. Third, in line with Heywood and Parker (1997), it is unlikely that the suggested analogy initially will be a perfect match across the compared domains, and it might be stimulating for the class to explore how far it can be taken, provided there is appropriate encouragement and guidance from the teacher. Fourth, and a theme to be further explored in the section on collaborative approaches to science education, a suggestion from a student to see the taught topic in terms of another offers an alternative to the common pattern of triadic dialogue in the classroom, where teachers ask questions (with an assumed correct answer in mind), students reply and the teachers provide feedback (Lemke, 1990). Spontaneous analogies are attractive starting points for 'genuine dialogue', in which students are provided the opportunity to 'talk science', which, according to Lemke, sadly, is unusual in the science classroom. Carroll and Mack (1985) investigated how metaphors were used in learning to use computer text editors (the forerunner of word processors such as Microsoft Word), including comparisons to a mechanical typewriter or the layout of a physical desk top. Based on an active learning approach, they argue that metaphors are open-ended and therefore inherently incomplete. In this respect, 'the relationships comprising a metaphor comparison are not "read off", but constructed by actively working through the implications of the metaphor' (Carroll \& Mack, 1985, p. 49). For example, at the time of the study, the typewriter metaphor was helpful in orienting novice computer users of how to handle a computer-based text editor, but similarities or discrepancies would have to be explored actively, such as what happens when you type two keys at the same time, which would lead to types jamming in the mechanical typewriter. In line with these thoughts, they suggest: 'Active learning implies that effective metaphors will 
be self-generated by learners, and that working out the implications of these metaphors will be a principle process of learning' (Carroll \& Mack, 1985, p. 50).

In relation to his study on expert scientists' problem solving (Clement, 1988), Clement (1987) has also investigated how college students spontaneously recruit analogies when they are asked to solve qualitative physics problems individually. Between themselves, 16 college freshmen produced and used 34 clearly articulated analogies as part of their problem solving. Some of them led to incorrect answers to the problem, but others helped the students solve the problem and led to impressive generalisations, indicating an underlying process of conceptual change. Clement (1987, p. 11) concludes: 'This suggests that analogies are an intuitive form of reasoning that could be tapped or taken advantage of in instruction to a greater extent than is currently done.' Similarly, Kaufman, Patel and Magder (1996) studied the spontaneous use of analogies in problem-solving exercises related to cardiovascular physiology. They asked 15 subjects of varying experience - ranging from medical school freshmen to practicing and academic cardiologists - to solve problems that were categorised as pertaining to basic physiology, pathophysiology or clinical issues in a 'think-aloud' manner. Due to their limited experience, novices mainly recruited analogies from the physical world, including physics theories and mundane comparisons to, for instance, a garden hose, in order to explain the phenomena at hand. The more expert participants drew comparisons from their clinical experience in order to articulate and elaborate upon complex explanations. Analogies were found to be used productively in many cases, but they could also lead to wrong answers, reflecting underlying misconceptions. They conclude that in order to be able to create meaningful analogies, students would need to have an adequate knowledge of the target domain prior to the exercise. 
Such use of spontaneous analogy is not unique to tertiary teaching. Cosgrove (1995) observed students at age 14 who studied the electric circuit, where they were supposed to devise a theory by means of analogical reasoning based on two analogies provided by the teacher. However, before the teacher presented the prepared analogies, one of the students came up with another analogy: 'I asked an electrician; it's like a train carrying coal. It drops it off, then goes back to get some more coal' (Cosgrove, 1995, p. 299), although later admitting that he had made up the story about asking the electrician in order to be taken seriously. This spontaneous analogy was recognised by the teacher and used and elaborated on in class throughout the teaching covering several lessons, mapping the continuous motion of the train to the electric current, and delivery of coal to energy transfer when passing resistances in the form of light bulbs. As more complex circuits were introduced, the analogy was modified through testing ideas in discussions among the students to fit the phenomena. Enghag and Niedderer (2005) performed a study on upper secondary school students working with two week miniprojects in physics. A group of four girls chose to design a demonstration of series and parallel electric circuits for lower secondary school students. The group expressed bewilderment regarding the observation that all light bulbs in a series circuit shone with the same strength, reflecting a well-known misconception: that electric current is conceptualised as getting consumed when it goes around a circuit. They managed the situation by coming up with a crocodile analogy, where positive and negative charges correspond to boys and girls at the opposite banks of a river trying to reach the other side. At first, they said that crocodiles that eat the children correspond to resistance; the fewer children the less electricity. In order to explain the equal brightness of the bulbs, however, they changed the explanation so that the children are not eaten by the crocodiles, but slowed down in their passage across the river, corresponding to 
decreased current in the circuit. The net speed forward is unchanged in the passage, corresponding to the equal brightness phenomenon. May, Hammer and Roy (2006) found that even third-grade students spontaneously use analogies in learning, and give the example of a student who creates an analogy to explain how the melting of ice cubes effects the water level by comparison to a rock falling into lava. In line with Clement (1987), they argue that students' spontaneous use of analogies is a capability or resource that can be utilised more in education. Similarly, Jacobson and Wickman (2007) have identified spontaneous metaphors that were generated by children aged 6-10 years when working with different science themes. Typical examples brought up by the children are that the hairy, extended female bud of a hazel tree looks like a caterpillar and that wet soil feels like spinach. Although arguably focusing on perceptually based surface similarities, such metaphors were found helpful for the children in understanding the encountered phenomena by relating them to their previous experiences and to everyday language.

In conclusion, as teachers we may be more attentive to the inherent ability of students - even young ones - to spontaneously generate their own analogies and metaphors, which may provide a still too rare opportunity for them to engage in 'talking science' (Lemke, 1990). As pointed out by Zook (1991), it is not an easy task for novices in a field spontaneously to see it as related to another, to find suitable source domains. Overall, however, the available research evidence shows that on occasions when students do come up with an analogy or metaphor of their own, with recognition and encouragement from teachers, it may serve as a starting point for an extended exploration of how far the comparison may be taken. 


\section{Self-generated analogies}

The use of self-generated analogy in teaching means encouraging students explicitly to generate their own analogies for encountered concepts or phenomena. In comparison to spontaneous analogy, explicit instruction to try to come up with analogies alters the pragmatic constraint (Holyoak \& Thagard, 1989) of the situation. To the best of my knowledge, Zeitoun (1984) was the first to suggest the idea of self-generated analogy in science teaching, with the aforementioned student self-developed analogy strategy, although the approach was not elaborated to a great extent and not regarded as particularly promising for learning of difficult concepts, due to the difficulty for students to identify suitable source domains. Middleton (1991) suggests the introduction of self-generated analogies in biology teaching, with a particular emphasis on stimulating students' critical thinking and creativity. Similarly, in their review of different approaches to creativity in science education, Kind and Kind (2007) bring forward analogy, and particularly students' generation of their own analogies, alongside imaginative thought as ways to stimulate students' creative thinking. One potential in exercises where students are asked to come up with their own analogies, as opposed to grasping the moments where they do so spontaneously, is that they can be asked to generate several analogies, or 'as many as possible', analyse their suitability and select particularly promising ones for further elaboration. As suggested by Spiro, et al. (1989), a next step might be to try to integrate these multiple analogies, but another approach could be to emphasise the incompatibility of different explanatory paradigms of a phenomenon (Kuhn, 1970). As pointed out by Linder (1993), depending on the theoretical outlook and experimental set-ups in quantum physics, light might be framed in terms of particles, or, alternatively, as a wave phenomenon, but never both of them at the same time; they are incompatible, yet complementary. Once again, analogies may 
help in conveying an important aspect of the nature of science.

David Wong (1993a, 1993b) has contributed substantially to the development of self-generated analogy as an approach in science education practice and research, in putting it on a solid theoretical ground and providing empirical examples of students' reasoning. As mentioned earlier, Wong (1993a) criticises transmissive teaching, where teachers are supposed to lead and students to follow passively. Instead he calls for constructivist approaches which make maximum use of students' prior knowledge of the encountered phenomena. In reference to among others Schön's (1993) account of scientists' use of generative metaphor, students should be allowed to work on meaningful problems, engaging in concrete activity with the phenomena. In practice, Wong presented eleven preservice teacher students to a piston/cylinder device and the phenomena that the force required to pull or push the plunger increases the further the gas is either compressed or decompressed when the nozzle is covered by a finger, and that, when released, the plunger returns to the original position. Working individually, the participants were first asked to explain the experienced air pressure phenomena, evaluate their explanations and try to identify any inadequacies. Second, they were asked to generate their own analogies for the phenomena, and specify in what respects the compared domains were similar or different. Third, they were asked to evaluate the analogies and modify them or come up with new analogies, carried out in an iterative fashion. Wong provides the example of the student Barb, who came up with a peoplein-a-room analogy, in which the gas is compared to mingling people, as at a party. Barb used the analogy with excitement to explain how the people would bump into each other more when crammed together, which represented the compression problem well, but found it more difficult to apply to the decompression and return phenomena. After some puzzlement, she realised that she would have to consider the air outside the 
cylinder in order to account for these phenomena. As another example, Bert came up with a series of analogies, including rubber balls or balloons in a container and stretching a person on a torture rack. Other participants suggested other examples of stretching in relation to the decompression phenomena, such as rubber bands and tugof-war situations. In all, ten of the eleven students exposed significant changes in their explanations of the phenomena throughout the exercise, but the students also expressed other types of insight, such as coming to reflect on their previous understanding of the phenomena and formulate unanswered problems.

Pittman (1999) points out that presenting teacher-generated analogies to students relies only implicitly on their pre-existing knowledge. Instead, the use of self-generated analogies seems to resonate better with genuinely constructivist ambitions. Accordingly, Pittman performed a study on 189 biology students in grade 7 and 8 , who took a twoweek unit on protein synthesis in their regular science class. After one week of regular instruction and introduction to analogies, the students worked in groups of three or four to create their own analogies for the topic following the GMAT sequence (Zeitoun, 1984). Pittman found that the girls performed significantly better than the boys on multiple choice tests on content knowledge one month after the unit, but that the boys outperformed the girls on a drawing test, where they were asked to represent the topic and relationships between its involved concepts. In all, student-generated analogies were found to be a useful tool for formative assessment of students' conceptions. James and Scharmann (2007) studied the outcomes of a course on methods for teaching science for preservice elementary teachers. A treatment group was introduced to generation of analogies, asked to find analogies for rocket propulsion in order to explain Newton's Third Law in group exercises and to construct practice lessons based on the analogies. A control group was taught to develop explanations by eliciting students' 
ideas prior to teaching, which was used to develop lessons for force and motion concepts in group exercises. The outcome, an increase in correct responses to questions on Newton's Third Law as measured by the Force Concept Inventory (Hestenes, Wells, \& Swackhammer, 1992) is worth noting: ' ... a remarkable difference in posttest measures of Newtonian conceptual understanding [53.8\% in comparison to $27.6 \%$ in the pretest] was found as a result of two extremely brief demonstration lessons that were presented to the treatment group to highlight the use of pedagogical analogies' (James \& Scharmann, 2007, p. 581). It is worth noting that these studies by Pittman (1999) and James and Scharmann (2007) were based on group-work analogy-generation exercises, a theme to expand upon in the following, although the emphasis of the analyses lies on the effect of students' generation of their own analogies, rather than on characterising their discourse throughout the process.

Mozzer and Justi (2012) report on a study where 13- to 14-year-olds were asked to generate analogies for chemical bonding in clinical interviews before and after a teaching sequence on the subject. In the interviews after the teaching, the students were able to identify limitations in the analogies they had generated beforehand, corresponding to the acquired knowledge, and elaborate them, e.g. by incorporating repulsive forces between atoms in a molecule in their analogies. In line with Pittman (1999), self-generated analogies was found to be a useful approach to formative assessment, giving teachers insight into the students' thought processes.

Apart from its potential role in facilitating learning, asking people to generate analogies for a common topic may be used to expose their different perspectives on the field. In this vein, Lancor (2012) asked students in introductory university biology, chemistry, and physics to generate analogies for energy in different contexts and found 
that they conceptualised energy in ways that were qualitatively different across the fields of study.

Although out of the immediate scope of this review, the approach of asking students to generate their own analogies has been adopted also in areas outside science education. Blanchette and Dunbar (2000) performed a study on analogical reasoning, where the issue of achieving zero budget deficit in financial politics was the target domain for learning. In the production paradigm, undergraduate students were found to be able to generate their own analogies that focused on relational structures, rather than on surface similarities, both in individual and group exercises. In contrast, in the reception paradigm, where students were asked to choose from a set of potentially fitting source domains, they tended to focus on surface similarities. Mayo (2001) compared teaching with teacher-generated analogies, student-generated analogies and a no analogy set-up in a college course on developmental psychology. The teachergenerated analogy group was provided with a set of common analogies, such as 'human development is like climbing a staircase', which were matched with developmental theories and discussed in class. The student-generated analogy group was instructed to generate its own analogies, which were criticised in class discussions, while the no analogy group read additional texts on the topic. In multiple choice tests after the exercises, the student-generated analogy group performed significantly better than the teacher-generated analogy group, which in turn, significantly outperformed the noanalogy group.

In conclusion, empirical psychological and educational studies of the use of selfgenerated analogies give a predominantly positive picture. The approach has been found to be conducive to a focus on relational structure and leads to better learning gains, as compared to teacher-generated analogies or no-analogy approaches, as well as a useful 
tool for formative assessment. As exemplified by Wong (1993a), the engagement with a particular analogy should not end with having identified a suitable source domain. Instead, students should be encouraged explicitly to point out correspondences across the domains and where the analogy breaks down, evaluate the utility of a particular analogy and, if possible, modify it against the background of improved understanding of the phenomena. However, it is still worth thinking over potential challenges that are intrinsic to the approach. As opposed to the disciplines of conducting research or product development, where the ultimate goal is to expand the knowledge of man, a main goal of science education is for students to appropriate ideas that have been sanctioned in science and by the educational system. This goal has to be kept in mind also when conducting analogy-generation exercises, giving a direction to, but also putting constraints on, the students' creativity.

\section{Heuristic analogies and mutual alignment}

One difference between the reception and production paradigms is that in the former, there is a seemingly correct answer to be found, while this is not necessarily the case in the latter, where you, in the capacity as researcher or student, engage in the exploration of how two domains might be connected. From this perspective, Wong (1993b) uses the students' analogies for air pressure phenomena presented above (Wong, 1993a) as an example where students' prior knowledge is incomplete or poorly organised:

In these situations, ideal analogies that lead quickly to understanding cannot be constructed. Learning from analogies in these conditions can be viewed as generative, where conceptual growth emerges from a continual refinement and synthesis of fragmented, incomplete knowledge (Wong, 1993b, pp. 1259-1260).

Similarly, Duit, Roth, Komorek and Wilbers (2001) distinguish between post-festum analogies and heuristic analogies. As researchers or teachers, we generate post-festum 
analogies when we have the required background knowledge and want to convey particular aspects of a domain to others, such as students, our colleagues or the general public. In contrast, generation of heuristic analogies refers to the process where we use analogies to explore the connection between domains of which we only have limited prior knowledge. This kind of cognitive processing may be used when conducting research, but also by students, both when interpreting teacher-generated analogies or exploring their own self-generated analogies. Wilbers and Duit (2006) describe the process of generating heuristic analogies in detail and point to its iterative and hypothesis-generating character, where more concepts and connections between them are added gradually, in coming to understand the target domain and how it relates to the source domain.

Duit, et al. (2001) provide the case of how upper secondary students were introduced to the physics of chaos and non-linear systems as an example of how students use heuristic analogies in science teaching. The students were encouraged to interact with a magnetic pendulum referred to as the 'Mercedes star', consisting of a suspended iron bob which would be attracted by three magnets, resulting in chaotic motion. They were asked to account for the phenomenon, including the description of surprising and unpredicted behaviour, in group work. Halfway into the exercise, the students were given a 'chaos bowl', a bowl with three partitions, separated by sloping ridges, but not told that the motion of a ball in the bowl might be seen as analogous to the 'Mercedes star'. In conjunction with a computer simulation of the magnetic pendulum, the students were found to make use of analogical reasoning in order to identify shared features of chaotic systems, such as the sensitivity to small changes in the starting position and the existence of sensitive zones of unstable equilibrium. The study shows that the small-group interactions contributed to a focus on the intended 
structural similarities and a deeper understanding of the workings of the magnetic pendulum. However, this did not occur spontaneously, but required specific hints from the teacher - for instance, the students were given drawings describing the structure of the magnetic pendulum in terms of ridges and walls and told that they might be helpful in understanding chaos - as well as substantial discussion time within the groups.

Although Wilbers and Duit (2006) claim that the distinction between postfestum and heuristic analogies is missing in prior theories of analogical reasoning, such as Gentner's (1983) structure-mapping theory, I would argue that their ideas fit well with those brought to the fore by Kurtz, Miao and Gentner (2001) in adopting the notion of mutual alignment:

\footnotetext{
In mutual alignment, the learner is simultaneously presented with two analogous situations that act symmetrically in the mapping process: Both serve as potential sources and recipients of information. We suggest that this kind of comparison between two partially understood situations can lead to noticing parallel structure and developing a deeper understanding of both situations (Kurtz, et al., 2001, p. 418).
}

Kurtz, et al. (2001) point out that one potential motivation for the use of mutual alignment in teaching is that, in contrast to traditional source-target analogies, it does not rely on memory retrieval of one of the domains, an activity which has been found to be challenging and often lead to a focus on superficial similarities. Instead, it works through a more symmetrical mechanism of bootstrapping between the two domains, a notion which, as we have seen, also has been adopted by Nersessian (2008) in the context of historical scientists' theory development. Kurtz, et al. (2001) conducted two experiments where undergraduate students were exposed to two analogous heat flow scenarios. A combination of having the students interpret the scenarios jointly, point out what they have in common, and explicitly match corresponding elements led to a 
significantly better focus on relevant structural similarities and differences, as compared to groups who only matched elements or interpreted the scenarios jointly, but not in combination, or interpreted the scenarios separately.

Clement's work (e.g. 1987, 1988, 1993; 2009; Stephens \& Clement, 2010) on non-formal model-based reasoning in science and science education is another line of research that has taken an interest in analogical reasoning as a process. As we have seen, Clement shows that analogies are often used in conjunction with other non-formal, intuitive ways of reasoning, such as visual imagery.

In my mind, encouraging students to engage in heuristics analogical reasoning, mutual alignment and bootstrapping provide particularly attractive teaching approaches for topics that are seen as difficult for a particular age group, involving the introduction of qualitatively new ways of thinking. In this respect, the choice of Wilbers and colleagues (Duit, et al., 2001; Wilbers \& Duit, 2006) to study learning of chaotic phenomena was probably not a coincidence, since the students could have been expected to have limited experience of thinking about and a limited vocabulary for talking about such phenomena. Another set of phenomena that might be suitable for these approaches to teaching are those that have been gathered by Chi (2005) under the notion of emergent processes. In contrast to direct processes (somewhat problematically exemplified by blood circulation, with distinct functions of the involved organs and the representative unidirectional motion of individual blood cells, which help us to structure the phenomenon), emergent processes are characterised by random, independent behaviour of its constituent parts, which form a pattern at the aggregate, macroscopic level. Three examples of emergent processes are osmosis, heat conduction and the electric circuit. The scientific accounts of these phenomena share an underlying structure of random motion of its constituent parts which add up to a net flow at the 
macroscopic level. Chi argues that these emergent processes are difficult to learn about, and require qualitatively new ways of thinking, but share a number of domain-general characteristics. If approached in a mutual alignment teaching framework, students would be presented with these phenomena and corresponding accounts in parallel, told that they have things in common, made aware of that they differ in other respects (e.g. that the moving entities involved in osmosis are atoms, molecules or ions, electrons in the electric circuit and energy quanta exchanged in collisions in heat conduction), asked to work out the correspondences and where the analogy breaks down. Although these phenomena are all invisible at the microscopic level, students may find one of these contexts more accessible than the others. For instance, osmosis means that more particles go through a semipermeable wall in one direction than in the other. This microscopic mechanism is simpler than those of heat conduction and the electric circuit, which both involve a net flow of energy at collisions of particles. Once a pattern has been discerned in one context, it is likely to be easier to recognise it also in the others. If the students in this way were asked to identify the shared structure across the phenomena, they would have to engage in analogical reasoning, develop their own vocabulary for the phenomena and in this process construct their own understanding of the mechanisms. Using Gentner's (1983) classification, identifying such shared structure across examples by means of analogy is possibly a more accessible route to teaching than explicitly describing and naming it in terms of the abstraction of emergent phenomena.

The issue of presenting several examples of a shared underlying structure may also be seen as adhering to the ideas of variation theory, developed by Marton and colleagues (e.g. Marton, 2006), according to which learning can be brought about only if there is both sameness and difference in some respect. Nothing can be learnt or 
transferred from interaction with only one example. Some aspects have to remain constant, and others be allowed to vary, if we are to discern common underlying principles. Typically, variation theory is used in order to make students aware of different critical features within a domain. However, I suggest that it might also be used to bring to attention the shared structure across domains where the involved physical entities are allowed to vary, a structure that would be difficult to discern based on teaching in one domain or based on one example of the principle only.

\section{Collaborative approaches to student-generated analogy}

Lemke (2001) provides a review of how different lines of research assuming sociocultural perspectives on learning have picked up interest in science education throughout the preceding two decades, resulting in an impressive and influential body of research. Emphasising for example social aspects of learning, the influence of the different cultures we live in and the different situations and contexts we are confronted with, such perspectives developed in opposition to existing traditions that focused on universal ways of reasoning and exclusively cognitive perspectives on learning. Sociocultural perspectives frame students' learning as their participation in the activities and discourse of a tradition or culture. In this perspective, being able to communicate and engage in interaction with others is integral to learning, and Lemke (1998) describes learning science as in many respects similar to learning a new language. In the investigation of such broader issues, going beyond the cognition of the individual learner, researchers assuming sociocultural perspectives have come to adopt other methods for collection and analysis of data than in cognitive traditions. For instance, in doubting the potential of techniques such as clinical interviews in the Piagetian tradition or multiple-choice tests in offering a direct route to an individual's conceptions, 
ethnographic methods or discourse analysis (e.g. Gee, 2005) provide more subtle ways to study the complexity of people's interaction.

Even though the study of analogical reasoning has originated from the field of cognitive psychology, it is surprising that only a few studies on the use of analogies in science education have taken an explicit interest in issues and results that have been brought to the fore within sociocultural traditions. Against this background, Heywood (2002, p. 233) argues in favour of a shift of perspectives:

...the research enterprise should shift focus from determining the effectiveness of analogy in cognitive transfer from base to target domains towards the recognition of the role of analogy in generating engagement in the learning process. In such a paradigm, meaning in science for both learner and teacher is derived from discourse rather than being independent of it.

Similarly, in their discussion of how models and analogies may be put to use in science education, Coll, France and Taylor (2005) argue that advances in sociocultural or socioconstructivist research have not yet informed the field sufficiently. In particular, they suggest that social approaches such as collaborative small-group work and whole-class argument hold the promise of enhancing model-based learning, involving for instance analogical reasoning, which has previously had a primarily individual focus.

The thought of having students engage in analogical reasoning in collaboration with their peers or in whole-class settings is not unique or entirely new - see for example the studies by Cosgrove (1995), Pittman (1999), Duit, et al. (2001) and James and Scharmann (2007) related to above, but it seems to have gathered an increasing interest in science education research lately. The trend also relates to the idea of in vivo studies of cognition (Dunbar \& Blanchette, 2001), looking at authentic practices in the sense of studying what might actually happen in school, where students tend to interact with each other and their teachers, rather than in isolation in a psychology laboratory, 
sharing with sociocultural perspectives the recognition of the importance of the context. It may be worth mentioning that taking an interest in social aspects of analogical reasoning does not diminish its deeply cognitive and constructivist character. It is more a matter of making full use of the social environment of parents, teachers and peers in each individual's learning, providing the learners with appropriate scaffolding (Wood, Bruner, \& Ross, 1976) or helping them to enter their zone of proximal development (Vygotsky, 1962). In this respect, using Holyoak and Thagard's (1989) framework of constraint satisfaction, collaborative approaches to analogical reasoning offer other pragmatic constraints than those involved in purely individual approaches.

The following review of collaborative approaches to analogies in science education retains a focus on studies that have been conducted within the production paradigm, in the sense that the learners themselves have been active in creating the analogies, rather than applying or enacting analogies suggested by teachers or researchers.

Lucia Mason and colleagues (Mason, 1996, 2004; Mason \& Sorzio, 1996) have studied analogical reasoning in classroom settings. Mason (1996) studied a class of fourth graders, where the children were introduced to three phenomena related to air pressure and instructed to generate analogies through collaboration in small groups and full-class discussions. The first set of analogies were quite close to the studied phenomena, focusing on surface attributes and affected by the students' alternative conceptions, such as 'water is like glue' as an explanation for why a piece of cardboard sticks to a glass filled with water when turned upside down. Gradually, the students came to focus on structural aspects and recognise the structural similarity between the three phenomena, reminding of the approaches of heuristic analogy (Duit, et al., 2001) and mutual alignment (Kurtz, et al., 2001). In an experimental study on the learning of 
heat transfer among fifth graders, Mason and Sorzio (1996) found that students that had to construct their own analogies between heat flow and water flow built a deeper understanding than students that were given the structural similarities by the teacher or not exposed to analogy at all. These results on heat flow were supported and extended in a related study by Mason (2004) among eighth graders.

Aubusson, Fogwill and colleagues (Aubusson \& Fogwill, 2006; Aubusson, Fogwill, Barr, \& Perkovic, 1997; Fogwill, 2010) have developed the approach of engaging students in simulation role play as a kind of personal analogy (Duit, 1991), where the students are asked to simulate the processes of natural phenomena by playing the roles of the constituent entities. Aubusson, et al. (1997) introduced simulation role play in three Australian secondary classes in the teaching of electricity and the human circulatory system, respectively, with the ambition that the students would participate actively in the design, in order to develop their own mental models for the phenomena. As a result, they found that the exercises had several positive effects. First, the role plays provided a non-threatening atmosphere for learning and the students enjoyed the exercises. Second, the students assumed ownership of their learning and deepened the understanding of the phenomena. Third, role play was found to be particularly useful for mixed-ability classes, since the students could take on different levels of responsibility in designing the play, explaining it and the phenomena to others, or merely participate or observe. In addition, the exercises enabled students to move around in order to learn, which is otherwise unusual in science classes. Aubusson and Fogwill (2006) further report on a study where secondary chemistry students were invited to cooperate in the development of an analogy role play involving formation and dissolution of chemical bonds, where the students acted as atoms and ions. They found that the approach offered an opportunity for the students to express, negotiate and develop their 
understanding in conversation as the analogy role play developed, encompassing new features gradually throughout the course of three lessons. Fogwill (2010, p. xii) comments on the findings of these and related studies in his doctoral dissertation:

...the majority of students were able, with support, to develop and use their own analogies to foster and display appropriate deep understandings about complex science concepts. By developing, using and sharing analogies, students made their conceptions and misconceptions 'visible'. In the supportive classroom environment, the identification of and discussion about students' alternative conceptions and misconceptions assisted students to develop appropriate scientific understandings. In general the understandings developed were persistent over long periods of time. The data suggests that co-generating analogies enhances student engagement and leads to deep understanding of challenging science concepts. It is thus concluded that the generation of analogies for science phenomena contributes positively to students' learning in science.

Spier-Dance, Mayer-Smith, Dance and Khan (2005) provide another example of students enacting their analogies, in this case in undergraduate introductory chemistry teaching of the oxidation of halogens. After initial teaching on the subject, the students were introduced to the concept of analogies in teaching and were given the homework exercise to individually come up with one analogy each for the subject and to bring it to class next time. The following session, they were divided into groups of five to six, given time to discuss the analogies and select one which would be acted out for the rest of the class. After the performances, the instructor led full-class discussions on how the analogy-based performances related to the represented phenomena and concepts. The outcome is intriguing:

The students who generated their own analogies performed significantly better in the exam and demonstrated a greater level of conceptual understanding than students who were presented with a teacher-derived analogy. It is particularly noteworthy that lower-achieving students who devised and enacted analogies for 
their peers significantly out-performed their counterparts who received more traditional instruction (Spier-Dance, et al., 2005, p. 163).

Similarly, Bellocchi and Ritchie (2011) investigated the use of analogy role play and analogy generation in small-group work among secondary chemistry students. They found such exercises to stimulate hybridisation between the students' own experiences from their everyday life and the scientific accounts of the studied phenomena, expressed as merged discourse and generation of hybrid, portmanteau words. For instance, a happy person representing a positively charged ion merged into a novel 'perso-ion'. Another case was a word play, pronouncing the neurotransmitter GABA as 'gaybar', which inspired an analogy between the studied phenomenon involving GABA and the students trying to persuade a doorman to let them into a night club.

Haglund and Jeppsson (2012) have conducted a study involving eight preservice physics teacher students' collaborative generation of analogies, where the students were introduced to the use of analogies in teaching and given descriptions of two different thermodynamic processes involving ideal gases. The students were divided into two groups of four, asked to explain the phenomena and come up with as many analogies for them as they could, scrutinise how far the analogies could be pushed and where they would break down. They would then pick out one or two of the analogies for presentation to the other group and the researchers, and finally they had the opportunity to modify their analogies in their small groups. The students in both groups were found to generate a large number of analogies, all of which involved microscopic accounts for the phenomena, where the particles in the gas were compared to, among other things, mingling people at a party, bouncing balls and angry bees in a jar. These examples are reminiscent of the ones identified by Wong (1993a), with the exception that there were no macroscopic analogies such as tug-of-war or rubber-band comparisons. The students 
were found to elaborate analogies that they had come up with themselves to a greater depth than analogies that were recalled from prior teaching. However, this difference in depth of elaboration is not attributed to conceptual challenges, but to the students assuming ownership (Enghag \& Niedderer, 2008) for their own analogies; there is no perceived need to scrutinise the lecturer's analogies, but only the students themselves can explore how far their own analogies can be pushed. In conclusion, self-generated analogies were found to be an effective approach to providing students with the opportunity to 'talk science' (Lemke, 1990). Haglund, Jeppsson and Andersson (2012) also adapted the approach of using self-generated analogies to a class of first graders. First, the children were introduced to analogies in a whole class setting, in terms of 'other things that work in the same way'. Next, they were divided into small groups for predict-observe-explain (POE) experiments (White \& Gunstone, 1992) with two phenomena: heat flow from a hot-plate to a frying pan, and a board with marbles of two colours which would tend to mix. Finally, they were asked to generate analogies for the phenomena and represent them through drawings individually, but sitting next to each other. As a result, the children had no problems understanding the idea of what analogies are in the whole-class introduction. For instance, they proposed adequately that a bicycle's handlebars would correspond to a car's steering wheel, in spite of superficially dissimilar appearances, lending support to Goswami’s (1992) view that young children can engage in analogical reasoning, provided the involved domains are familiar. In addition, some of the children managed to come up with their own comparisons with a predominately relational focus, i.e. analogies, also for the encountered phenomena, which was particularly impressive in light of the rather abstract involved concepts, such as heat and mixing. 
In an effort to go beyond narrative descriptions of classroom interaction Stephens and Clement (2010) describe a methodology for identifying evidence of three types of non-formal reasoning in scientific modelling in the classroom: analogies; extreme cases, such as thinking through how a system would behave at zero vs. extremely high temperatures or velocities; and Gedanken experiments (thought experiments), e.g. Einstein's imagining of what it would be like to travel alongside a ray of light. They exemplify how the methodology can be used with two case studies of high school physics classes working with normal forces and gravity, respectively. As opposed to previous psychology laboratory studies of individuals' problem solving, Stephens and Clement notice cases of distributed reasoning across the participants in these classroom settings. They therefore distinguish between a spontaneously generated analogy, where a student comes up with the idea of comparing domains, and a spontaneously run analogy, where a student - possibly different from the one who generated the analogy - draws conclusions for the target domain from the analogy. As examples of their findings, in the class working with normal forces, the students preempted the teacher in collaboratively generating a set of bridging analogies between a book on a table and a hand pressing down a spring, involving pliable materials such as plywood and cardboard (cf. Clement, 1993). When reasoning about the effect of the earth's rotation on gravity in the other class, one of the students compared this to what would happen if you were taped to a rotating ball in free space, and argued that you would feel a centrifugal force. Intriguingly, in this example the student managed to combine all three described non-formal ways of reasoning: he made an analogy between the rotating ball and earth scenarios, took the mass and rotation of the ball to extreme values in comparison to the planet-human system, and finally ran through the Gedanken 
experiment of what would happen to the ball-human system, which he had not experienced in practice.

Lin et al. (2012) provide another study with a more structured approach to analysing analogy generation in the classroom. They invited six classes of fourth-grade students (120 students in total) to carry out a series of ten collaborative reasoning exercises on controversial issues - such as whether zoos are good places for animals. Each class was divided into three groups. The first, third and ninth exercises were selected for detailed analysis with regards to the students' use of analogies in their discussions. On average, the researchers identified more than five analogies per discussion. Across the exercises, the students used significantly more analogies, and more students contributed with analogies, the longer into the series they went. In addition, the proportion of comparisons with a focus on relational structure tended to increase throughout the exercises. An interesting feature of the discussions is that the use of analogies tended to snowball, which shows how the children benefited from the social interaction: once one student introduced an analogy into the discussion, other students would follow the same way of reasoning and come up with more analogies, and the time interval to subsequent analogies would decrease. The authors conclude:

Extending previous research on social collaboration and cognitive development, the present study suggests that experience in a stimulating social environment enabled children to exceed what might otherwise have been individual cognitive limits and collectively make rapid progress in understanding and producing analogies (Lin, et al., 2012, p. 13).

However, once again, it is worth giving a word of caution. Yerrick, Doster, Nugent, Parke and Crawley (2003) studied preservice physics teachers working with analogies for electric circuits in small-group exercises within a guided-inquiry approach. While strategically inserted teacher-generated analogies effectively led the students to 
ascertain their own beliefs, when the analogies were adapted in small-group discussions, they tended to promote misconceptions and to be over-generalised in contexts where they did not apply. In particular, self-generated analogies, corresponding to the students' personal theories, were found to divert them from the focus on the studied phenomena, leading to incorrect conclusions, and unconstructive group dynamics. In line with Clark (2006), this is an example where the students, left by themselves without teacher guidance, were found to develop idiosyncratic explanations in the exercises. In addition, in their context of analogy role play, Aubusson, et al. (1997) found that the students at times confused the role play with the represented phenomena, such as imagining that electrons can think and make decisions of what path to take when enacting electric circuits.

Overall, the recent trend of studying students' generation of their own analogies in social settings could be of interest both within the research tradition that has looked into analogies in science education and among scholars who adopt sociocultural perspectives on science education, but have hitherto not taken an interest in analogies. From the point of view of research on analogies, the social setting provides an opportunity to come up with more potential source domains and scrutinise them from more perspectives than individual students would be able to do by themselves. The peer group provides the zone of proximal development (Vygotsky, 1978) for each of its participants. Conversely, within a sociocultural framework, collaborative generation of analogies has been found to be an effective instructional tactic in order to make students engage in 'talking science' (Lemke, 2001). After all, if sociocultural perspectives on learning are to expand upon or go beyond purely cognitive approaches, rather than merely ignoring them, attending to analogies, arguably 'the core of cognition' (Hofstadter, 2001), might be a good starting point. 
Finally, with an emphasis on the cultural dimension of sociocultural theories, we must not forget that in school students are supposed to gradually appropriate our shared traditions in society. In the case of science education, a main goal for students is to acquire the knowledge that has found sanction in science and develop competence with regards to procedures to attain such knowledge. Collaborative approaches to analogical reasoning can contribute to students' learning in terms of appropriating such sanctioned knowledge, or in other words making it into their own.

\section{Educational implications and a future outlook}

The present review focuses on the two trends of attending more to students' analogies in science teaching and, in this endeavour, of making more use of the social setting in small groups or the classroom. As we have seen, there are obstacles to learning by use of analogies, and some of them relate exclusively to the production paradigm and social settings, such as identifying suitable source domains against a background of insufficient knowledge of the target domain or destructive group dynamics. However, the overall conclusion of this review is that use of student-generated analogies - be it of the spontaneous or encouraged self-generated kind - may be beneficial to students' engagement and learning of taught topics, and contribute to their understanding of the nature of science, particularly through interaction with peers in role play, argumentation or small-group problem-solving exercises. One may wonder then, how come these ideas have developed only during the last decades? Part of the answer is probably to be found in the Piagetian influence in Western education, with its primary focus on individuals' cognitive development and the claim that children develop the ability for abstract thought and, particularly, for analogical reasoning at a quite late stage. There is also the teachers' legitimate worry that their students may develop misconceptions and 
idiosyncratic explanations as part of such exercises (Clark, 2006; Zook, 1991), leading away from accepted science knowledge.

So, if we leave the work of coming up with representations of encountered phenomena, such as analogies and drawings, to the students themselves, does that mean that we dispense with the teacher? On the contrary, I would argue that the role of the teacher is still crucial. First, the teacher has the responsibility to develop inspiring exercises that involve a stretched target for learning, which is challenging but not impossible. In order to be able to engage in analogical reasoning, the students need to have some prior knowledge both of the target domain and of a range of potentially useful source domains. As we have seen, for particularly challenging content, introducing qualitative new ways of reasoning, encouraging heuristic analogical reasoning (Duit, et al., 2001) or mutual alignment (Kurtz, et al., 2001), may be worth considering. Next, when carrying out analogy-generating exercises, teachers would have to engage in constant interaction with the students, in order to make sure that they do not go get stuck in idiosyncratic reasoning or destructive group dynamics. Individual analogies may prove non-productive in representing the phenomena at hand or just be too complex for the students at their current level of understanding (Haglund \& Jeppsson, 2012). When using analogies in the production paradigm, as in other studentcentred approaches, students should not be left alone, but need appropriate guidance and scaffolding through careful instructional design and interaction with their teachers (e.g. Brown \& Campione, 1994; Hmelo-Silver, Duncan, \& Chinn, 2007). In addition, as pointed out by Mozzer and Justi (2012) and Pittman (1999), asking for students' own analogies for a phenomenon offers good opportunities for formative assessment. Even if the students come up with explanations and analogies that are at odds with the sanctioned view in science and the teacher's intentions with the topic, at least the 
teacher gets to know about what they think and can do something about it. Finally, I would like to emphasise that adherence to the production paradigm in analogygeneration exercises does not invalidate the insights behind the structures and individual steps in previously suggested approaches to teaching with analogies, including GMAT (Zeitoun, 1984), TWA (Glynn, 1989) and the FAR guide (Treagust, et al., 1998). In this respect, Zeitoun's (1984) framing of self-generated analogy as a teaching strategy - a mode of delivery of the GMAT - is particularly attractive. All these approaches stress that students have to grasp - preferably through personal engagement of some kind - in what respect individual analogies can be used productively and where they break down. As pointed out by Heywood and Parker (1997), learning happens in the analysis of analogy-breakdown, and it is up to the teachers to make sure that such analysis is carried through.

Another important practical question is at what stage of teaching an exercise involving student-generated analogies should be introduced. As pointed out by Kaufman, et al. (1996), among others, students need an adequate knowledge of the target domain before they can come up with analogies for it. However, herein lies a fundamental dilemma, related to Plato's $(1976,80 \mathrm{e})$ paradox of the Meno:

[A] man cannot search either for what he knows or what he does not know. He cannot search for what he knows - since he knows it, there is no need to search nor for what he does not know, for he does not know what to look for.

Kaufman et al. (1996, p. 383) propose a possible way to resolve the dilemma: ‘...an instructor may follow an iterative process with initial explanations of scientific phenomena, followed by analogies which could be used strategically to extend, refine and deepen students' understanding'. This type of iterative approach is also found in Mozzer and Justi's (2012) study, where students are invited to elaborate analogies they 
come up with throughout a course and captured in Duit, et al.'s (2001) description of the processing of heuristic analogies. These ideas also resonate well with the sociocultural perspective on learning, where students are seen as gradually coming to appropriate an aspect of our culture, rather than a matter of either having or not having acquired a particular concept.

Another issue is what educational implications we should draw from particular analogies that individual students or groups of students have come up with and have found inspiring, and that have led to productive exploration of the analogy and the represented phenomenon. If one group of students successfully compared neurotransmitters to entering a gay bar or discussed about particles as if they behave like angry bees, should we introduce these particular analogies when teaching the topics at hand? It might be worth considering, but that it is off the point with regards to the production paradigm: That coming up with these analogies was found useful and led to engaged dialogue among some groups of students is not a guarantee that another group of students will react in the same way. More fundamentally, however, if these particular analogies were to be conveyed to other students, it would be a case of adhering to the reception paradigm, based on other people's comparisons, rather than encouraging the students to make use of their own associations and experience.

A key area for future research study on analogical reasoning in science education is the relation to the specificities of language. In research on the cognitive basis of scientific modelling, Amin (2012) argues that after a phase of recognition of experts' non-formal patterns of reasoning (e.g. Clement, 1988), in explicit opposition to propositional, language-based approaches, there has been a phase of interest in the role of distributed cognition (Hutchins, 1995), involving the role of interaction with the social and material environment in cognition. In speculating about a potential third 
phase, Amin suggests that language is 'the missing artefact', and that research so far has avoided this perspective due to its connection to the previous focus on propositional logic.

$\mathrm{Amin}^{2}$ sees a parallel with research on metaphors and analogies in that it has changed from a traditionalist linguistic focus to a view on metaphors as built upon cognition in terms of analogical reasoning. This cognitive trend is represented by for example Gentner's (1983) structure-mapping theory and the emergence of the field of cognitive linguistics. Lakoff and Johnson $(1980,1999)$ have been influential in the development of cognitive linguistics, including identifying the phenomenon of conceptual metaphor, systematic mappings between abstract and concrete domains, which are grounded in our embodied experience and unconsciously help us to structure language and thought. Fauconnier and Turner (1998) have contributed to the field with their description of conceptual blending, where structure from several conceptual input domains are coordinated and projected to a 'blended' domain, which in turn may be blended with yet more input domains, reminiscent of the way Maxwell made use of his insight into several different domains in his development of the electromagnetic theory (Nersessian, 2008). Recently, there has been an increasing interest in how science education may take advantage of conceptual metaphor (e.g. Amin, 2009; Amin, Jeppsson, Haglund, \& Strömdahl, 2012; Brookes \& Etkina, 2007; Jeppsson, Haglund, Amin, \& Strömdahl, 2013; Niebert, Marsch, \& Treagust, 2012; Scherr, Close, McKagan, \& Vokos, 2012) and conceptual blending (Podolefsky \& Finkelstein, 2007). As an example, in a collaborative problem-solving exercise, two physical chemistry $\mathrm{PhD}$ students were asked to account for the process of placing a beaker with water in a

\footnotetext{
${ }^{2}$ Personal communication.
} 
freezer. One of the students productively invited to think through what would happen 'if I take heat from this beaker... and move over to the room' (Jeppsson, et al., 2013, p. 93), i.e. if heat is transferred from the water in the beaker to the surrounding air in the freezer. The expression does not immediately come across as figurative, but it may be interpreted as an example of conceptual metaphor involving reification (Sfard, 1994), i.e. talking of something abstract - in this case heat, which in thermodynamics is a process variable - as if it were an object, like a burning coal, which can be manipulated by hand. The reification of heat enables the student to engage in mental imagery (Stephens \& Clement, 2010), involving identification and interaction with the phenomenon (Ochs, Gonzales, \& Jacoby, 1996). However, the example also shows how analogical reasoning is used in conjunction with narrative language (Bruner, 1991) in order to establish a shared understanding with the collaborative partner, going beyond the view of language as a superficial superstructure on top of cognition.

As we have seen, science education recently has taken an increasing interest in collaborative analogical reasoning. In light of notions such as ZPD (Vygotsky, 1978) and scaffolding (Wood, et al., 1976), science education researchers and practitioners have realised that collaborative approaches are conducive to learning. However, I think that Heywood's (2002) suggestion to focus on the role of analogy in science discourse and in the generation of student engagement has not yet been attended to sufficiently from an analytical point of view. Lemke (1990) provides brief examples of how teachers may use analogies as a structural strategy or technique in science discourse in the classroom and Cameron (2003) offers insightful analyses of how metaphors are involved in classroom discourse, with many examples taken from science topics. More such studies on the role of analogies and metaphors in authentic classroom discourse would be a valuable contribution to the field. 


\section{Acknowledgement}

I would like to thank my colleagues within the Swedish National Graduate School in Science and Technology Education (FontD), in particular Helge Strömdahl, my supervisor during the doctoral studies, Fredrik Jeppsson and Tamer Amin, the collaboration with whom has been an indispensable part of coming to understand the use of analogies and metaphors in science education.

\section{Notes on contributors}

Jesper Haglund is a lecturer in Science Education at Linköping University, Sweden. He completed his $\mathrm{PhD}$ on analogies in science education in 2012. His research focuses on the use of scientific models, metaphors, analogies and visualisation technology in thermodynamics education.

\section{References}

Ainsworth, S., Prain, V., \& Tytler, R. (2011). Drawing to learn in science. Science, 333(6046), 1096-1097.

Amin, T. G. (2009). Conceptual metaphor meets conceptual change. Human Development, 52(3), 165-197.

Amin, T. G. (2012). Researching scientific modeling: Language, the missing artifact. In E. Abbey \& S. Surgan (Eds.), Developing methods in psychology (pp. 141-182). New Brunswick, NJ: Transaction Publishers.

Amin, T. G., Jeppsson, F., Haglund, J., \& Strömdahl, H. (2012). The arrow of time: metaphorical construals of entropy and the second law of thermodynamics. Science Education, 96(5), 818-848.

Atkins, L. J. (2004). Analogies as categorization phenomena: Studies from scientific discourse. Doctoral Dissertation, University of Maryland, College Park, MD. Retrieved 17 April, 2013 from http://drum.lib.umd.edu/handle/1903/2040.

Aubusson, P. J., \& Fogwill, S. (2006). Role play as analogical modelling in science. In P. J. Aubusson, A. G. Harrison \& S. M. Ritchie (Eds.), Metaphor and analogy in science education (pp. 93-104). Dordrecht, the Netherlands: Springer.

Aubusson, P. J., Fogwill, S., Barr, R., \& Perkovic, L. (1997). What happens when students do simulation-role-play in science? Research in Science Education, 27(4), 565-579. 
Aubusson, P. J., Harrison, A. G., \& Ritchie, S. M. (Eds.). (2006). Metaphor and analogy in science education. Dordrecht, the Netherlands: Springer.

Bellocchi, A., \& Ritchie, S. M. (2011). Investigating and theorizing discourse during analogy writing in chemistry. Journal of Research in Science Teaching, 48(7), 771-792.

Black, M. (1962). Models and metaphors: studies in language and philosophy. Ithaca, NY: Cornell University Press.

Blanchette, I., \& Dunbar, K. (2000). How analogies are generated: The roles of structural and superficial similarity. Memory \& Cognition, 28(1), 108-124.

Bowdle, B. F., \& Gentner, D. (2005). The career of metaphor. Psychological Review, $112(1), 193-216$.

Boyd, R. (1993). Metaphor and theory change: What is "metaphor" a metaphor for? In A. Ortony (Ed.), Metaphor and thought (2nd ed., pp. 481-532). Cambridge, UK: Cambridge University Press.

Brookes, D. T., \& Etkina, E. (2007). Using conceptual metaphor and functional grammar to explore how language used in physics affects student learning. Physical Review Special Topics - Physics Education Research, 3(1), 010105.

Brown, A. L. (1989). Analogical learning and transfer: What develops? In S. Vosniadou \& A. Ortony (Eds.), Similarity and analogical reasoning (pp. 369-412). Cambridge, UK: Cambridge University Press.

Brown, A. L., \& Campione, J. C. (1994). Guided discovery in a community of learners. In K. McGilly (Ed.), Classroom lessons: integrating cognitive theory and classroom practice (pp. 229-270). Cambridge, MA: MIT Press.

Bruner, J. S. (1991). The narrative construction of reality. Critical Inquiry, 18(1), 1-21.

Cameron, L. (2003). Metaphor in educational discourse. London, UK: Continuum.

Carroll, J. M., \& Mack, R. L. (1985). Metaphor, computing systems, and active learning. International Journal of Man-Machine Studies, 22(1), 39-57.

Chalmers, D. J., French, R. M., \& Hofstadter, D. R. (1992). High-level perception, representation, and analogy: A critique of artificial intelligence methodology. Journal of Experimental \& Theoretical Artificial Intelligence, 4(3), 185-211.

Chi, M. T. H. (2005). Commonsense conceptions of emergent processes: Why some misconceptions are robust. Journal of the Learning Sciences, 14(2), 161-199. 
Clark, D. (2006). Longitudinal conceptual change in students' understanding of thermal equilibrium: An examination of the process of conceptual restructuring. Cognition and Instruction, 24(4), 467-563.

Clement, J. (1987). Generation of spontaneous analogies by students solving science problems. Paper presented at the International Conference on Thinking (3rd), Honolulu, HI, January 4-8, Honolulu, HI.

Clement, J. (1988). Observed methods for generating analogies in scientific problem solving. Cognitive Science, 12(4), 563-586.

Clement, J. (1993). Using bridging analogies and anchoring intuitions to deal with students' preconceptions in physics. Journal of Research in Science Teaching, 30(10), 1241-1257.

Clement, J. (2009). Creative model construction in scientists and students: the role of imagery, analogy, and mental simulation. Dordrecht, NL: Springer.

Cohen, L. (1992). Anthem. On The Future. New York, NY: Columbia Records.

Coll, R. K., France, B., \& Taylor, I. (2005). The role of models/and analogies in science education: implications from research. International Journal of Science Education, 27(2), 183-198.

Cosgrove, M. (1995). A study of science-in-the-making as students generate an analogy for electricity. International Journal of Science Education, 17(3), 295-310.

Dagher, Z. R. (1998). The case for analogies in teaching science understanding. In J. J. Mintzes, J. H. Wandersee \& J. D. Novak (Eds.), Teaching science for understanding: a human constructivist view (pp. 195-211). San Diego, CA: Academic.

diSessa, A. A. (2004). Metarepresentation: Native competence and targets for instruction. Cognition and Instruction, 22(3), 293-331.

Duit, R. (1991). On the role of analogies and metaphors in learning sciences. Science Education, 75(6), 649-672.

Duit, R., Roth, W.-M., Komorek, M., \& Wilbers, J. (2001). Fostering conceptual change by analogies - between Scylla and Charybdis. Learning and Instruction, 11(4-5), 283-303.

Dunbar, K. (1995). How scientists really reason: scientific reasoning in real-world laboratories. In R. J. Sternberg \& J. E. Davidson (Eds.), The nature of insight (pp. 365-395). Cambridge, MA: MIT Press. 
Dunbar, K., \& Blanchette, I. (2001). The in vivo/in vitro approach to cognition: the case of analogy. Trends in Cognitive Sciences, 5(8), 334-339.

Enghag, M., \& Niedderer, H. (2005). Physics learning with exploratory talks during a mini-project - a case of four girls working with electric circuits. Journal of Baltic Science Education, 1(7), 5-11.

Enghag, M., \& Niedderer, H. (2008). Two dimensions of student ownership of learning during small-group work in physics. International Journal of Science and Mathematics Education, 6(4), 629-653.

Falkenhainer, B., Forbus, K. D., \& Gentner, D. (1989). The structure-mapping engine: Algorithm and examples. Artificial Intelligence, 41(1), 1-63.

Fauconnier, G., \& Turner, M. (1998). Conceptual integration networks. Cognitive Science, 22(2), 133-187.

Fogwill, S. (2010). Student co-generated analogies and their influence on the development of science understanding. Doctoral Dissertation, University of Technology, Sydney, Australia. Retrieved 17 April, 2013 from http://utsescholarship.lib.uts.edu.au/dspace/handle/2100/1244.

Gee, J. P. (2005). An introduction to discourse analysis: theory and method (2nd ed.). New York, NY: Routledge.

Gentner, D. (1983). Structure-mapping: A theoretical framework for analogy. Cognitive Science, 7(2), 155-170.

Gentner, D. (1989). The mechanisms of analogical learning. In S. Vosniadou \& A. Ortony (Eds.), Similarity and analogical reasoning (pp. 199-241). Cambridge, UK: Cambridge University Press.

Gentner, D. (2003). Why we're so smart. In D. Gentner \& S. Goldin-Meadow (Eds.), Language in mind: Advances in the study of language and thought (pp. 195236). Cambridge, MA: MIT Press.

Gentner, D., Bowdle, B. F., Wolff, P., \& Boronat, C. (2001). Metaphor is like analogy. In D. Gentner, K. J. Holyoak \& B. K. Kokinov (Eds.), The analogical mind: Perspectives from cognitive science (pp. 199-254). Cambridge, MA: MIT Press.

Gentner, D., \& Gentner, D. R. (1983). Flowing waters or teeming crowds: mental models of electricity. In D. Gentner \& A. L. Stevens (Eds.), Mental models (pp. 99-129). Hillsdale, NJ: Lawrence Erlbaum Associates. 
Gentner, D., Holyoak, K. J., \& Kokinov, B. K. (Eds.). (2001). The analogical mind: Perspectives from cognitive science. Cambridge, MA: MIT Press.

Gentner, D., \& Jeziorski, M. (1993). The shift from metaphor to analogy in Western science. In A. Ortony (Ed.), Metaphor and thought (2nd ed., pp. 447-480). Cambridge, UK: Cambridge University Press.

Gentner, D., \& Stevens, A. L. (Eds.). (1983). Mental models. Hillsdale, NJ: Lawrence Erlbaum Associates.

Gick, M. L., \& Holyoak, K. J. (1980). Analogical problem solving. Cognitive Psychology, 12(3), 306-355.

Glucksberg, S., \& Keysar, B. (1990). Understanding metaphorical comparisons: Beyond similarity. Psychological Review, 97(1), 3-18.

Glynn, S. M. (1989). The teaching with analogies model. In K. D. Muth (Ed.), Children's comprehension of text: Research into practice (pp. 185-204). Newark, DE: International Reading Association.

Goswami, U. (1992). Analogical reasoning in children. Hove, UK: Lawrence Erlbaum Associates.

Haglund, J. (2012). Analogical reasoning in science education - connections to semantics and scientific modelling in thermodynamics. Retrieved 28 January, 2013, from http://liu.divaportal.org/smash/record.jsf?searchId=1\&pid=diva2:571154.

Haglund, J., \& Jeppsson, F. (2012). Using self-generated analogies in teaching of thermodynamics. Journal of Research in Science Teaching, 49(7), 898-921.

Haglund, J., Jeppsson, F., \& Andersson, J. (2012). Young children's analogical reasoning in science domains. Science Education, 96(4), 725-756.

Harel, I., \& Papert, S. (Eds.). (1991). Constructionism: research reports and essays, 1985-1990. Norwood, NJ: Ablex.

Harrison, A. G., \& Coll, R. K. (Eds.). (2008). Using analogies in middle and secondary science classrooms: the FAR guide - an interesting way to teach with analogies. Thousand Oaks, CA: Corwin Press.

Hesse, M. B. (1966). Models and analogies in science. Notre Dame, IN: University of Notre Dame Press.

Hestenes, D., Wells, M., \& Swackhammer, G. (1992). The force concept inventory. The Physics Teacher, 30(3), 141-158. 
Heywood, D. (2002). The place of analogies in science education. Cambridge Journal of Education, 32(2), 233-247.

Heywood, D., \& Parker, J. (1997). Confronting the analogy: primary teachers exploring the usefulness in the teaching and learning of electricity. International Journal of Science Education, 19(8), 869-885.

Hmelo-Silver, C. E., Duncan, R. G., \& Chinn, C. A. (2007). Scaffolding and achievement in problem-based and inquiry learning: A response to Kirschner, Sweller, and Clark (2006). Educational Psychologist, 42(2), 99-107.

Hofstadter, D. R. (2001). Epilogue: Analogy as the core of cognition. In D. Gentner, K. J. Holyoak \& B. K. Kokinov (Eds.), The analogical mind: Perspectives from cognitive science (pp. 499-538). Cambridge, MA: MIT Press.

Holyoak, K. J. (2012). Analogy and relational reasoning. In K. J. Holyoak \& R. G. Morrison (Eds.), The Oxford handbook of thinking and reasoning (pp. 234-259). Oxford, UK: Oxford University Press.

Holyoak, K. J., \& Thagard, P. (1989). Analogical mapping by constraint satisfaction. Cognitive Science, 13(3), 295-355.

Hutchins, E. (1995). Cognition in the wild. Cambridge, MA: MIT Press.

Jacobson, B., \& Wickman, P.-O. (2007). Transformation through language use: children's spontaneous metaphors in elementary school science. Science \& Education, 16(3-5), 267-289.

James, M. C., \& Scharmann, L. C. (2007). Using analogies to improve the teaching performance of preservice teachers. Journal of Research in Science Teaching, 44(4), 565-585.

Jeppsson, F., Haglund, J., Amin, T. G., \& Strömdahl, H. (2013). Exploring the use of conceptual metaphors in solving problems on entropy. Journal of the Learning Sciences, 22(1), 70-120.

Kaufman, D. R., Patel, V. L., \& Magder, S. A. (1996). The explanatory role of spontaneously generated analogies in reasoning about physiological concepts. International Journal of Science Education, 18(3), 369-386.

Kind, P. M., \& Kind, V. (2007). Creativity in science education: Perspectives and challenges for developing school science. Studies in Science Education, 43(1), $1-37$. 
Knudsen, S. (2003). Scientific metaphors going public. Journal of Pragmatics, 35(8), 1247-1263.

Kuhn, T. S. (1970). The structure of scientific revolutions (2nd ed.). Chicago, IL: University of Chicago Press.

Kurtz, K. J., Miao, C.-H., \& Gentner, D. (2001). Learning by analogical bootstrapping. Journal of the Learning Sciences, 10(4), 417-446.

Lakoff, G., \& Johnson, M. (1980). Metaphors we live by. Chicago, IL: The University of Chicago Press.

Lakoff, G., \& Johnson, M. (1999). Philosophy in the flesh. New York, NY: Basic Books.

Lancor, R. A. (2012). Using student-generated analogies to investigate conceptions of energy: A multidisciplinary study. International Journal of Science Education. doi: 10.1080/09500693.2012.714512.

Lemke, J. L. (1990). Talking science. Language, learning and values. Norwood, NJ: Ablex.

Lemke, J. L. (1998). Teaching all the languages of science: words, symbols, images and actions. Retrieved 10 January, 2011, from http://academic.brooklyn.cuny.edu/education/jlemke/papers/barcelon.htm.

Lemke, J. L. (2001). Articulating communities: Sociocultural perspectives on science education. Journal of Research in Science Teaching, 38(3), 296-316.

Lin, T.-J., Anderson, R. C., Hummel, J. E., Jadallah, M., Miller, B. W., Nguyen-Jahiel, K., et al. (2012). Children's use of analogy during collaborative reasoning. Child Development, 83(4), 1429-1443.

Linder, C. J. (1993). A challenge to conceptual change. Science Education, 77(3), 293300.

Marton, F. (2006). Sameness and difference in transfer. Journal of the Learning Sciences, 15(4), 499-535.

Mason, L. (1996). Collaborative reasoning on self-generated analogies: conceptual growth in understanding scientific phenomena. Educational Research and Evaluation, 2(4), 309-350.

Mason, L. (2004). Fostering understanding by structural alignment as a route to analogical reasoning. Instructional Science, 32(4), 293-318. 
Mason, L., \& Sorzio, P. (1996). Analogical reasoning in restructuring scientific knowledge. European Journal of Psychology of Education, 11(1), 3-23.

May, D. B., Hammer, D., \& Roy, P. (2006). Children's analogical reasoning in a thirdgrade science discussion. Science Education, 90(2), 316-330.

Mayo, J. A. (2001). Using analogies to teach conceptual applications of developmental theories. Journal of Constructivist Psychology, 14(3), 187-213.

Middleton, J. L. (1991). Student-generated analogies in biology. The American Biology Teacher, 53(1), 42-46.

Mozzer, N. B., \& Justi, R. (2012). Students' pre- and post-teaching analogical reasoning when they draw their analogies. International Journal of Science Education, 34(3), 429-458.

Nersessian, N. J. (2008). Creating scientific concepts. Cambridge, MA: MIT Press.

Niebert, K., Marsch, S., \& Treagust, D. F. (2012). Understanding needs embodiment: A theory-guided reanalysis of the role of metaphors and analogies in understanding science. Science Education, 96(5), 849-877.

Ochs, E., Gonzales, P., \& Jacoby, S. (1996). "When I come down I'm in the domain state": grammar and graphic representation in the interpretive activity of physicists. In E. Ochs, E. A. Schegloff \& S. A. Thompson (Eds.), Interaction and grammar (pp. 328-369). Cambridge, UK: Cambridge University Press.

Ortony, A. (Ed.). (1979/1993). Metaphor and thought (2nd ed.). Cambridge, UK: Cambridge University Press.

Piaget, J., Montangero, J., \& Billeter, J.-B. (1977/2001). The formation of analogies. In J. Piaget \& R. R. Campbell (Eds.), Studies in reflecting abstraction (pp. 139152). Hove, UK: Psychology Press.

Pittman, K. M. (1999). Student-generated analogies: Another way of knowing? Journal of Research in Science Teaching, 36(1), 1-22.

Plato. (1976). Meno (G. M. A. Grube, Trans.). Indianapolis, IN: Hacket Publishing Company.

Podolefsky, N. S., \& Finkelstein, N. D. (2007). Analogical scaffolding and the learning of abstract ideas in physics: An example from electromagnetic waves. Physical Review Special Topics - Physics Education Research, 3(1), 010109. 
Richland, L. E., Morrison, R. G., \& Holyoak, K. J. (2006). Children's development of analogical reasoning: Insights from scene analogy problems. Journal of Experimental Child Psychology, 94(3), 249-273.

Scherr, R. E., Close, H. G., McKagan, S. B., \& Vokos, S. (2012). Representing energy. I. Representing a substance ontology for energy. Physical Review Special Topics - Physics Education Research, 8(2), 020114.

Schön, D. A. (1993). Generative metaphor: A perspective on problem-setting in social policy. In A. Ortony (Ed.), Metaphor and thought (2nd Edition ed., pp. 137163). New York, NY: Cambridge University Press.

Sfard, A. (1994). Reification as the birth of metaphor. For the Learning of Mathematics, 14(1), 44-55.

Spier-Dance, L., Mayer-Smith, J., Dance, N., \& Khan, S. (2005). The role of studentgenerated analogies in promoting conceptual understanding for undergraduate chemistry students. Research in Science \& Technological Education, 23(2), 163178.

Spiro, R. J., Feltovitch, P. J., Coulson, R. L., \& Anderson, D. K. (1989). Multiple analogies for complex concepts: Antidotes for analogy-induced misconception in advanced knowledge acquisition. In S. Vosniadou \& A. Ortony (Eds.), Similarity and analogical reasoning. (pp. 498-531). Cambridge, UK: Cambridge University Press.

Stephens, A. L., \& Clement, J. J. (2010). Documenting the use of expert scientific reasoning processes by high school physics students. Physical Review Special Topics - Physics Education Research, 6(2), 020122.

Taber, K. S. (2001). When the analogy breaks down: modelling the atom on the solar system. Physics Education, 36(3), 222.

Treagust, D. F., Harrison, A. G., \& Venville, G. J. (1998). Teaching science effectively with analogies: an approach for preservice and inservice teacher education. Journal of Science Teacher Education, 9(2), 85-101.

White, R., \& Gunstone, R. (1992). Probing understanding. London, UK: The Falmer Press.

Wilbers, J., \& Duit, R. (2006). Post-festum and heuristic analogies. In P. J. Aubusson, A. G. Harrison \& S. M. Ritchie (Eds.), Metaphor and analogy in science education (pp. 37-49). Dordrecht, the Netherlands: Springer. 
Wong, E. D. (1993a). Self-generated analogies as a tool for constructing and evaluating explanations of scientific phenomena. Journal of Research in Science Teaching, 30(4), 367-380.

Wong, E. D. (1993b). Understanding the generative capacity of analogies as a tool for explanation. Journal of Research in Science Teaching, 30(10), 1259-1272.

Wood, D., Bruner, J. S., \& Ross, G. (1976). The role of tutoring in problem solving. Journal of Child Psychology and Psychiatry, 17(2), 89-100.

Vosniadou, S., \& Ortony, A. (Eds.). (1989). Similarity and analogical reasoning. Cambridge, UK: Cambridge University Press.

Vygotsky, L. S. (1962). Thought and language. Cambridge, MA: MIT Press.

Vygotsky, L. S. (1978). Mind in society: The development of higher psychological processes. Cambridge, MA: Harvard University Press.

Yerrick, R. K., Doster, E., Nugent, J. S., Parke, H. M., \& Crawley, F. E. (2003). Social interaction and the use of analogy: An analysis of preservice teachers' talk during physics inquiry lessons. Journal of Research in Science Teaching, 40(5), 443-463.

Zeitoun, H. H. (1984). Teaching scientific analogies: a proposed model. Research in Science \& Technological Education, 2(2), 107-125.

Zook, K. B. (1991). Effects of analogical processes on learning and misrepresentation. Educational Psychology Review, 3(1), 41-72. 